\title{
Recyclable Functionalized Polymer for Cu(II) Decontamination from Aqueous Media
}

\author{
LAVINIA TOFAN ${ }^{1}$, RODICA WENKERT ${ }^{2}$, ION BUNIA ${ }^{3}$, CARMEN PADURARU $^{1 *}$ \\ ${ }^{1}$ Department of Environmental Engineering and Management, "Cristofor Simionescu" Faculty of Chemical Engineering and \\ Environmental Protection "Gh. Asachi” Technical University of Iasi, 73 Prof. Dr.D. Mangeron Str., 700050, Iasi, Romania \\ ${ }^{2}$ Soroka University Medical Center, Beer-Sheva, Ragher, Israel \\ 3“"Petru Poni” Institute of Macromolecular Chemistry, 41A Grigore Ghica Voda Str., 700487, Iasi, Romania
}

\begin{abstract}
In the endeavor to explore more and more materials, this work is focused on the study of the potential applicability of a chelating sorbent based on an acrylic copolymer functionalized with amidoethylenamine groups in $\mathrm{Cu}(\mathrm{II})$ removal from wastewaters in batch and dynamic conditions. The proposed sorbent was synthesized by the chemical transformation reaction of ethylacrylate (EA): acrylonitrile (AN):2\% divinylbenzene (DVB) copolymer with ethylenediamine (EDA). Batch sorption results pointed out that the $\mathrm{Cu}(\mathrm{II})$ retention by the acrylic copolymer functionalized with amidoethylenamine groups was dependent on the initial solution $\mathrm{pH}$, initial metal concentration and contact time. The sorption of $\mathrm{Cu}$ (II) on the tested chelating copolymer obeyed both Langmuir and Freundlich isotherms. The Langmuir maximum sorption capacity was $65.21 \mathrm{mg} \mathrm{Cu}$ (II)/g of polymer. The kinetic experimental data fitted well with the pseudo - second order model. The dynamic behavior of a fixed bed column filled with the acrylic copolymer functionalized with amidoethylenamine groups has been studied in terms of breakthrough curve. The experimental breakthrough data have been well described by Thomas model. The tested chelating copolymer is suitable for multiple processes of Cu(II) sorptiondesorption. The column studies with real wastewater sample presented a removal efficiency of 100\% for $\mathrm{Cu}$ (II) and a significant improvement of the wastewater quality. The acrylic copolymer functionalized with amidoethyleneamine groups can be successfuly applied for the Cu (II) removal - recovery recycling.
\end{abstract}

Keywords: chelating polymer, copper, sorption, desorption, wastewater treatment

\section{Introduction}

Copper, found in the fourth period (group 11) of the periodic table is, at the same, an essential element and one of the most valuable metal with many and varied industrial applications [1,2]. Its strong toxicity, manifested even at low concentrations, strictly demands that the discharge of the in-dustrial wastewaters contaminated with copper in environment be preceded by applying of a proper treatment method for copper removal, such as: chemical precipitation, coagulation/ flocculation, ion exchange, cementation, membrane separation, reverse osmosis, electroflotation, sorption [3 - 5].

The prominence and popularity of the sorption by sorbents among all the removal methods out-lined above are mainly due to its high efficiency even at very low pollutant concentration, relative sim-plicity, flexibility, reversibility, kinetic and economic advantages, quality of the generated treated ef-fluents able to be re- used [6]. Amongst all the explored sorption materials, the chelating sorbents made up of a polymer network (support) carrying functional groups, capable of sequestering metal ions by coordinative bonds, are distinguished mainly by their broad spectrum of structures and physicochemical features, large uptake capacity, favorable sorption rate, important selectivity for different concentrations, reusability, adjustability of the surface chemistry and tolerance for a wide range of wastewater parameters [7]. New chelating sorbents based on 5-aminopyridine-2-tetrazole immobilized on cross-linked polystyrene, poly(acrylamide) modified with pendent benzothiazole groups, pyri-dinepyrazole ligands grafted onto polymethylhydrosiloxane, poly(6-(ethoxybenzothiazole acryla-mide), poly(MVE-alt-MA) polymer with Schiff base chelating groups, iminodiacetic acid functional-ized

*email: cpadur2005@yahoo.com 
D301 resin, glycidyl methacrylate grafted onto polystyrene resin have been recently reported in the literature as good performance materials for copper removal from aqueous media [8 - 13].

The goal of this research is to contribute to the broadening of the chelating polymers range with copper (II) sorption performances of significance for the development of copper recycling technology. In this context, the copper sorptive capability of an acrylic copolymer functionalized with amidoethylenamine groups has been evaluated through a comprehensive research. Batch experiments have been run for the influence of initial solution $p \mathrm{H}$ and concentration, contact time on the copper(II)uptake from mono-component aqueous solutions. Data of the batch studies have been processed by means of the equations of Langmuir and Freundlich isotherms. Kinetics of the sorption have been modelled with the aid of the well-known models. The dynamic behavior of the acrylic copolymer functionalized with amidoethylenamine groups-copper(II) sorption system have been studied in terms of breakthrough curve, which is the concept describing the performance of fixed bed column. The applicability of the Thomas and Yoon-Nelson models to the dynamic data have been evaluated. In order to assess the potential practical applicability of the proposed chelating copolymer, a desorption study of copper (II) from metal loaded and the removal of copper(II) from a sample of real wastewater has been performed

\section{Materials and methods}

\subsection{Materials}

To obtain the polymeric support of the acrylic sorbent the following materials were used: divinylbenzene (DVB) (80\% DVB; 20\% ethylvinylbenzene); acrylonitrile (AN), ethylacrylate (EA); toluene, benzoyl peroxide purum moisted with $20 \%$ water as initiator; ethylenediamine (EDA), $\mathrm{C}=98$ wt. \%; dichloroethane, all from Fluka; thiourea puriss p.a. from Riedel deHaen, 99 wt. \%.

In the sorption experiments, analytical grade $\mathrm{CuSO}_{4} \cdot 5 \mathrm{H}_{2} \mathrm{O}$ (Sigma-Aldrich), $\mathrm{H}_{2} \mathrm{SO}_{4}$ and $\mathrm{HCl}$ supplied from Merck\&Co have been used.

\subsection{Preparation of the functionalized acrylic copolymer}

The crosslinked acrylic copolymer was obtained by free radical suspension copolymerization in water of the mixture of mono-vinyl monomers. The reaction has been carried out in a glass reactor equipped with an anchor-type stirrer with possibility of stirring speed adjusting, heating stem and reflux condenser.

The reaction mixture is composed of two phases: (i) the aqueous phase containing $1200 \mathrm{~mL}$ distilled water and a polymeric stabilizer $(0.5 \mathrm{wt} . \%)$ prepared by the hydrolysis of poly (styrene-co-maleic anhydride) copolymer with aqueous $\mathrm{NH}_{3}$ solution;(b) the organic phase consisting of the mixture of (ethylacrylate (78 wt. \%) and acrylonitrile (20wt. \%) monomers, divinylbenzene( 2 wt. \%) as crosslinking agent, benzoyl peroxide( $1 \%$ of monomers amount) as initiator and toluene used as diluent at a dilution(D) of 0.4. Toluene content used throughout this study is calculated as follows [14]:

$$
\mathrm{D}=[\mathrm{mL} \text { diluent } /(\mathrm{mL} \text { diluent }+\mathrm{mL} \text { monomers })] \times 100
$$

The AN and DVB amounts have been calculated versus the entire amount of the monomers

The aqueous phase was added into the glass reactor and was stirred for $30 \mathrm{~min}$ at $40-45^{\circ} \mathrm{C}$.After this, the organic phase was added under continuous stirring. An organic to aqueous phase ratio of $1: 3(\mathrm{v} / \mathrm{v})$ was kept constant for all copolymerizations. The reaction of polymerization was left to proceed at $65^{\circ} \mathrm{C}$ for $4 \mathrm{~h}$ and then at $85^{\circ} \mathrm{C}$ for $8 \mathrm{~h}$. The yielded copolymer in the beads form was then sep-arated from the reaction medium by filtration, washed with warm distilled water to remove the suspen-sion stabilizer and dried at $50^{\circ} \mathrm{C}$. The removal of residual monomers, oligomers and diluent has been done by Soxhlet extraction with dichloroethane. The content of DVB in the copolymer was assumed as be the same with that of mixtures of monomers.

The tested acrylic sorbent with amidoethylenamine groups has been prepared by the chemical transformation of the yielded copolymer with EDA. The aminolysis-hydrolysis reaction of EA: AN: $2 \%$ DVB copolymer with EDA at a copolymer: amine ratio of $1: 3$ was performed at $110^{\circ} \mathrm{C}$ for $16 \mathrm{~h}$. For 
this purpose, the copolymer beads were brought into an aminolysis reactor provided with stirrer and descending refrigerant. After the reaction completion, the aminolyzed product has been filtered and washed with distilled water to remove the reagents excess. Then the material was treated with $4 \% \mathrm{HCl}$, filtered and further washed with distilled water until to neutral $p \mathrm{H}$. Afterwards, the prepared functionalized copolymer was treated with $4 \% \mathrm{NaOH}$, filtered and washed with distilled water until to neutral $p \mathrm{H}$. The operation was repeated 2-3 times for a complete purification.

Finally, the yielded sorbent has been analysed for density $(\mathrm{g} / \mathrm{mL})$, weight exchange capaci$\operatorname{ty}(\mathrm{mequiv} / \mathrm{mL})$ and volume exchange capacity (mequiv/mL) [14].

\subsection{Preparation of solutions}

Stock solutions of $1021 \mathrm{mg} \mathrm{L}^{-1}$ and were prepared by dissolution of analytical grade reagent $\mathrm{CuSO}_{4}$ $\cdot 5 \mathrm{H}_{2} \mathrm{O}$ in deionized water and was complexonometrically standardized. Working solutions of $\mathrm{Cu}$ (II) ions was prepared by the appropriate dilutions of the stock solutions.

A $10^{-2} \mathrm{~mol} / \mathrm{L}$ solution of $\mathrm{H}_{2} \mathrm{SO}_{4}$ was prepared by corresponding dilution and used in the medium acidity effect study.

\subsection{Batch sorption experiments}

Samples of about $0.05 \mathrm{~g}$ chelating sorbent were equilibrated with $25 \mathrm{~mL}$ of each aqueous solution containing defined amounts of $\mathrm{Cu}$ (II) ions at desired temperature and $p \mathrm{H}$. At the end of predetermined time intervals, the phases were separated by filtration. The $\mathrm{Cu}$ (II) ion concentrations in the final solutions were determined by atomic absorption spectrometry.

The parameters characteristic to the $\mathrm{Cu}$ (II) ions sorption by the acrylic copolymer functionalized with amidoethylenamine groups were calculated with the following equations:

Retention percentage, $\mathrm{R}(\%)$

Retained amount of metal ion, $\mathrm{q}(\mathrm{mg} / \mathrm{g})$

$$
\begin{aligned}
& \mathrm{R}=[(\mathrm{C} 0-\mathrm{C}) / \mathrm{C} 0] \cdot 100 \\
& \mathrm{q}=[(\mathrm{C} 0-\mathrm{C}) / \mathrm{G}] .
\end{aligned}
$$

where $\mathrm{C} 0$ is the initial concentration of metal ion $(\mathrm{mg} / \mathrm{L}), \mathrm{C}$ is the cation concentration after sorption $(\mathrm{mg} / \mathrm{L}), \mathrm{V}$ is the volume of solution $(\mathrm{L})$; and $\mathrm{G}$ is the weight of sorbent $(\mathrm{g})$.

\subsection{Dynamic sorption studies}

By packing successively samples of $0.6754 \mathrm{~g}$ and $0.6825 \mathrm{~g}$ of the acrylic copolymer functionalized with amidoethylenamine into a column of glass $(1.5 \mathrm{~cm}$ inner diameter and $15 \mathrm{~cm}$ in length), heights of bed of $6.8 \mathrm{~cm}$ and $7 \mathrm{~cm}$ have been achieved. For supporting the polymer during experiments a wadding glass layer was fitted at the column bottom. Solutions with $50 \mathrm{mg} / \mathrm{L}$ and $100 \mathrm{mg} / \mathrm{L}$ initial concentrations in $\mathrm{Cu}$ (II) have been fed to the column top. The flow rate was $2.5 \mathrm{~mL} / \mathrm{min}$. After collecting the samples of effluent at different times from the column bottom, their $\mathrm{Cu}$ (II) concentrations have been determined by atomic absorption spectrometry. The column operation has been stopped when inlet concentration of $\mathrm{Cu}(\mathrm{II})$ was approximately equaled with that at the outlet.

\subsection{Reusability studies}

Desorption and regeneration studies have been carried out in batch conditions. Samples of $0.1 \mathrm{~g}$ of $\mathrm{Cu}$ (II) loaded sorbent were contacted with $0.1 \mathrm{M} \mathrm{HCl}$ for $6 \mathrm{~h}$, under intermittent shaking. After mixture filtration, the amount of desorbed $\mathrm{Cu}$ (II) has been determined by atomic absorption spec-trometry. The regenerated spent functionalized copolymer under study has been reused, the batch sorp-tion and desorption being repeated 8 times.

\subsection{Treatment of sample of real wastewater}

The sample of wastewater has come from a municipal deposit of wastes collecting. After sampling, the wastewater sample have been prepared and analyzed for its significant parameters. For the dynamic 
sorption removal of $\mathrm{Cu}(\mathrm{II}), 1 \mathrm{~L}$ volume of wastewater has been passed through a column filled with the proposed functionalized copolymer in a bed of $6.8 \mathrm{~cm}$ height at a flow rate of $2 \mathrm{~mL} / \mathrm{min}$.

\subsection{Apparatus}

For the characterization of the functionalized copolymer, FT-IR spectrometer Bruker Vertex 70 and Bruker AXS-Microanalyse GmbH microscope have been used. The $\mathrm{pH}$ of solution was measured with the Comsort C $863 \mathrm{pH}$ - meter. The analysis for $\mathrm{Cu}$ (II) content has been performed on the $210 \mathrm{VGB}$ Buck Scientific atomic absorption spectrometer.

\section{Results and discussions}

\subsection{Synthesis and characterization of the tested acrylic sorbent}

Being more physically and chemically stable and with an enhanced hidrophilicity than the sty-rene supports, acrylic copolymers are of special interest for functionalization [15]. In light of this, the preparation of the chelating sorbent under study is based on the following sequence of reactions: the free radical suspension copolymerization in water of ethylacrylate (EA) and acrylonitrile (AN) with $2 \%$ DVB $\rightarrow$ the aminolysis-hydrolysis reaction of EA: AN: $2 \%$ DVB copolymer with ethylenediamine (EDA) at a copolymer: amine ratio of 1:3 (Scheme 1).

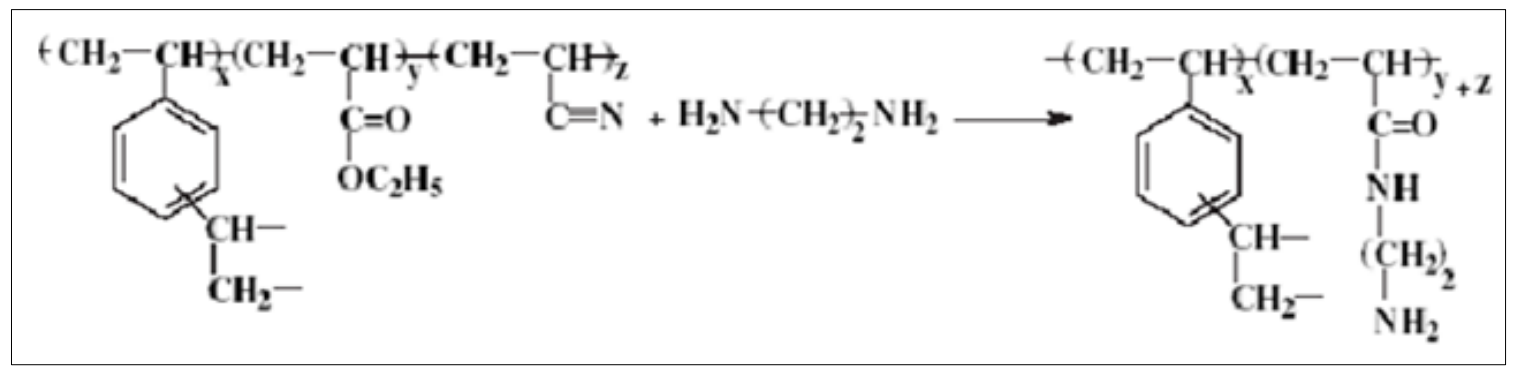

Scheme 1. Synthesis of the tested chelating polymer

It follows from Scheme 1 that the proposed sorbent is remarkable through the $\mathrm{N}$ and $\mathrm{O}$ - contain-ing groups which are recognized as being deeply involved in the efficient coordination interactions with copper ions $[6,16,17]$. The synthesized chelating copolymer is characterized by a volume weight of $0.0374 \mathrm{~g} / \mathrm{mL}$ and a weak exchange capacity of $0.29 \mathrm{meq} / \mathrm{mL}$ and $7.86 \mathrm{meq} / \mathrm{g}$, respectively.

In order to confirm this statement, infrared absorption spectra of the proposed functionalized acrylic copolymer before and after $\mathrm{Cu}$ (II) sorption have been recorded, being shown in Figure 1.

The highlighted modifications in the IR spectra in Figure 1 can be described as follows. Thus, in the region of $3500-3400 \mathrm{~cm}^{-1}$ appear bands that can be attributed to the $\mathrm{N}-\mathrm{H}$ bond, specific to the secondary amines of $\mathrm{R}_{2} \mathrm{NH}$ type. At $3081-2854 \mathrm{~cm}^{-1}$ there is an absorption band referring to the valence vibration and deformation of the $\mathrm{C}$ - $\mathrm{H}$ bonds. The decrease of peak in the $2131-2065 \mathrm{~cm}^{-1}$ region may be due to the valence vibration of the $\mathrm{C} \equiv \mathrm{N}$ or $\mathrm{N}=\mathrm{C}=\mathrm{O}$ bonds. The reduction of adsorption occurring at $1558.42-1557.45 \mathrm{~cm}^{-1}$ could be due to the valence vibration of the $\mathrm{C}=\mathrm{O}$ bond, but also to the $\mathrm{C}=\mathrm{C}$ bond in aromatic rings. At the same time, in this range appears the deformation vibration of the $-\mathrm{NH}_{2}$ bond, giving bands of low intensities. The region of $1392-1317 \mathrm{~cm}^{-1}$ is characterized by bands of me-dium intensity due to the deformation vibration of the $-\mathrm{CH}_{3}$ and $-\mathrm{CH}_{2}$ groups. The valence vibrations from the $1177-1038 \mathrm{~cm}^{-1}$ range are attributed to the $\mathrm{C}-\mathrm{O}$ and $\mathrm{C} \equiv \mathrm{N}$ bonds. The $854-848 \mathrm{~cm}^{-1}$ range is dominated by bands characteristic to the substitution due to the hydrogen atoms existing in the aro-matic ring. The disappearance of the vibration band at $708.81 \mathrm{~cm}^{-1}$ is connected with the presence of the aromatic groups in matrix, that are not affected by the complexation of metal [18]. 


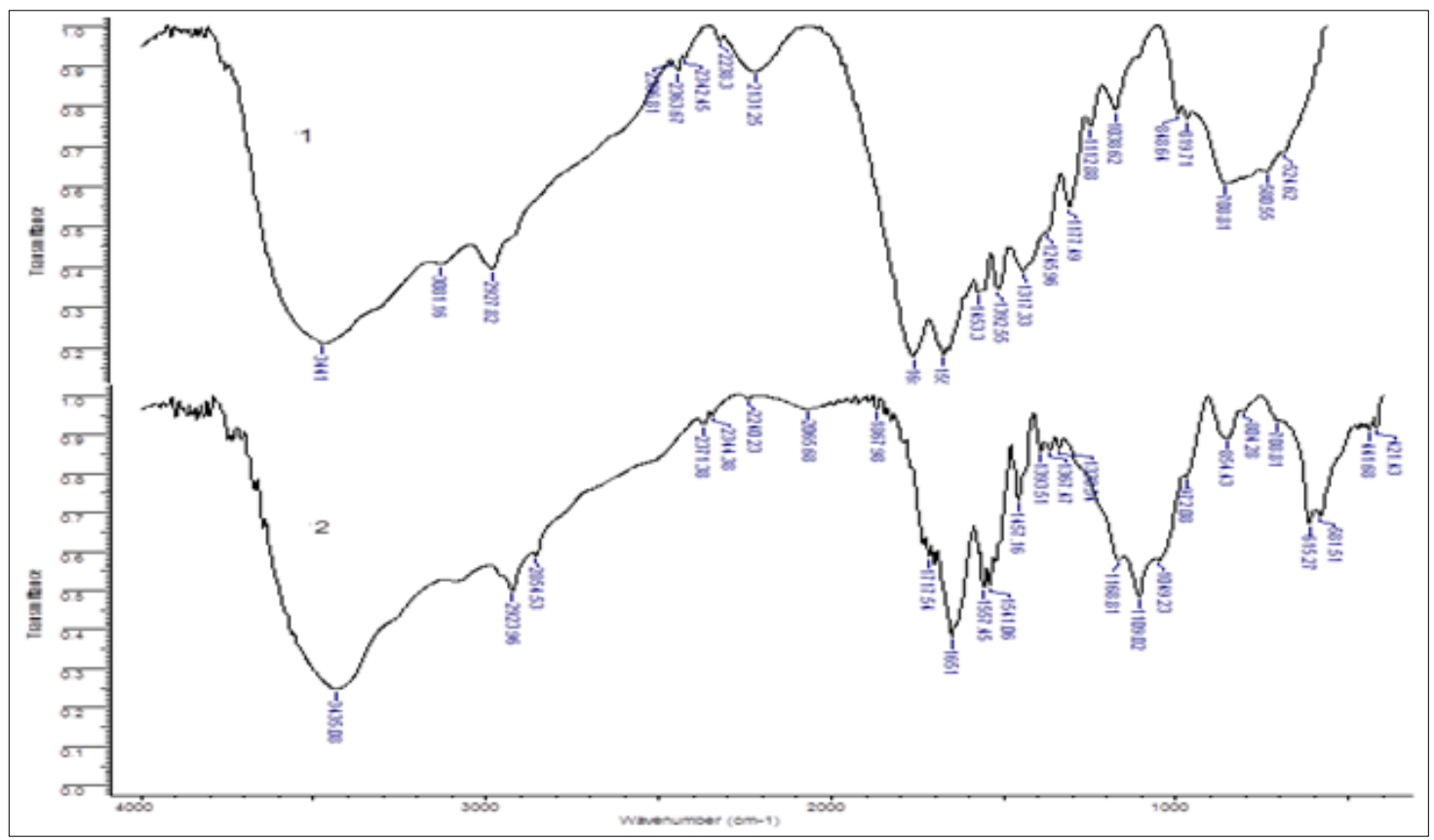

Figure 1. IR spectra: 1 - functionalized acrylic copolymer; 2- functionalized acrylic copolymer+Cu(II)

Some bands overlapping, appearing or shrinking at $1717 \mathrm{~cm}^{-1}$ and $1651 \mathrm{~cm}^{-1}$ show disappearance or movement to the smaller wave numbers of the carbonyl group presenting in the copolymer structure.

The band modification around $1100 \mathrm{~cm}^{-1}$ value suggest the possible protonation of the amine group [18], and the changes appearing at $1390 \mathrm{~cm}^{-1}$ value lead to the identification of the absorption characteristic to the protonated carboxylic group [19].

The disappearance, shrinking and/ or modification of the bands in the IR spectrum of the chelating sorbent loaded with the metal ion suggests the involvement of the $-\mathrm{NH}_{2}, \mathrm{C}=\mathrm{O}$ and $\mathrm{C}-\mathrm{O}$ groups and aromatic ring, respectively in the process of $\mathrm{Cu}$ (II) retention. A change of the peak position to the smaller wave numbers shows the weakness of the chemical bond, while the modification to higher wave numbers emphasizes a stronger bond [20]

The appearance of the absorption bands at $615 \mathrm{~cm}^{-1}$ and $518 \mathrm{~cm}^{-1}$ shows that the metal ion forms coordinate complexes with the oxygen and nitrogen existing in the copolymer matrix [21]

The analysis of the two IR spectra shows that, besides the electrostatic attraction between the metal ion and the sorbent, a mechanism based on chemical interactions could also be involved.

Scanning electron microscopy and energy-dispersion X-ray spectrometry (EDX) has been used for the morphological characterization of the functionalized copolymer and the proposed sorbent loaded with $\mathrm{Cu}$ (II) (Figure 2).

The analysis of the SEM images in Figure 2a reveals the presence of the $\mathrm{Cu}$ (II) ions on the surface of the particles. This finding is confirmed by the metal peak appeared in the EDX spectra given in Figure $2 b$. 


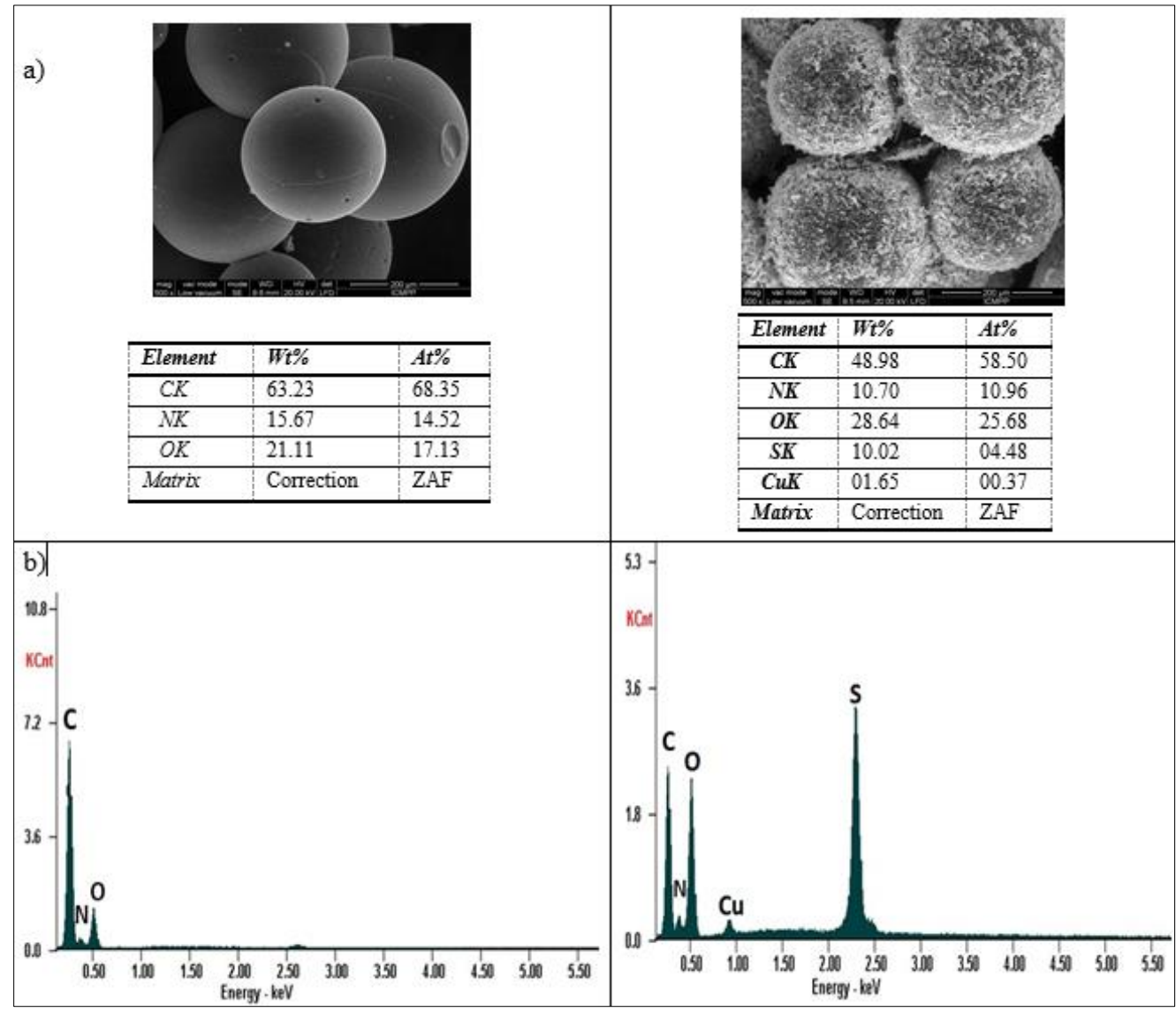

Figure 2. SEM images (a) and EDX spectra (b) for the tested chelating sorbent before and after $\mathrm{Cu}(\mathrm{II})$ sorption

\subsection{Batch sorption studies of $\mathrm{Cu}$ (II)}

In the batch sorption studies undertaken, the affinity of the acrylic copolymer functionalized with amidoethylenamine groups for $\mathrm{Cu}$ (II) ions has been assessed as function of $p \mathrm{H}$, concentration of the initial solution and contact time, respectively.

\subsubsection{Effect of initial solution $p H$}

The acrylic copolymer functionalized with amidoethylenamine groups exhibits a $\mathrm{Cu}$ (II) sorption behaviour which is highly dependent on the $p \mathrm{H}$ of initial solution (Figure 3). The avoidance of the $\mathrm{Cu}$ (II)precipitation is of stringent necessity. Therefore, the sorption experiments were performed using solutions with initial $\mathrm{Cu}(\mathrm{II})$ concentrations of $126.72 \mathrm{mg} / \mathrm{L}$ and initial $p \mathrm{H}$ varying from 1 to 5 . As follows from Figure 3, the $\mathrm{Cu}$ (II) sorption ability of the acrylic copolymer functionalized with amidoethylenamine groups shows an increasing trend when initial $p \mathrm{H}$ is changed from 1 to 5 , the maximum being reached at a $p \mathrm{H}$ value of 5. The explanation of this increasing trend relies on two factors with decisive action on the sorption performances of the acrylic copolymer under study: the protonation of the surface functional groups and the ionization degree of the metal ions. At low values of initial $p \mathrm{H}$, the surface change is positive due to the functional groups protonation and the excess of protons, so that the predominant kind of interaction with metal ions is the electrostatic repulsion and the chelating ability is very small. The increase of initial $p \mathrm{H}$ results in a marked decrease of the protonation degree, being favored strong coordination interaction, meaning copper complex formation via nitrogen atoms of the amidoethylenamine functional groups. 


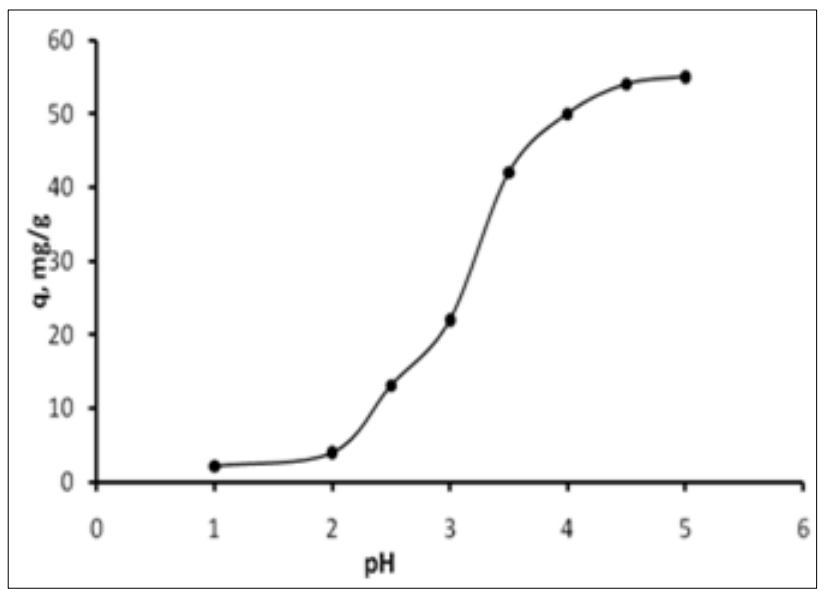

Figure 3. The influence of $p \mathrm{H}$ of initial solution on the sorption of

$\mathrm{Cu}(\mathrm{II})$ by the acrylic resin functionalized with amidoethylenamine groups $\left(\mathrm{C}_{0}=126.72 \mathrm{mg} \mathrm{Cu}(\mathrm{II}) / \mathrm{L}\right.$; sorbent dose $=2 \mathrm{~g} / \mathrm{L}$, time $=24 \mathrm{~h}, \mathrm{t}=20^{\circ} \mathrm{C}$ )

\subsubsection{Effect of initial concentration of $\mathrm{Cu}(\mathrm{II})$ solution}

The potential applicability of the acrylic copolymer functionalized with amidoethylenamine groups in the efficient removal of the tested heavy metal ion from industrial effluents with low content in $\mathrm{Cu}$ (II) is supported by the results describing the influence of initial concentration of $\mathrm{Cu}(\mathrm{II})$ in the batch sorption under study (Figure 4). As can be from Figure 4, the rise of initial concentration of $\mathrm{Cu}(\mathrm{II})(\mathrm{C} 0)$ from $42.24 \mathrm{mg} / \mathrm{L}$ to $338 \mathrm{mg} / \mathrm{L}$ leads to the decrease of the $\mathrm{Cu}(\mathrm{II})$ sorption percentage (R\%) from $94.02 \%$ to $75 \%$, respectively. This decreasing trend emphasizes the key role of the superficial amidoethylenamine groups in the $\mathrm{Cu}$ (II) sorption process [9]. Thus, at low initial $\mathrm{Cu}$ (II) concentration, the significant availability of the superficial amidoethylenamine groups determines large values of the $\mathrm{Cu}$ (II) sorption percentage. On the other hand, the saturation of the superficial functional groups occurring at high initial concentration of $\mathrm{Cu}(\mathrm{II})$ results in lower percentage of $\mathrm{Cu}(\mathrm{II})$ sorption.

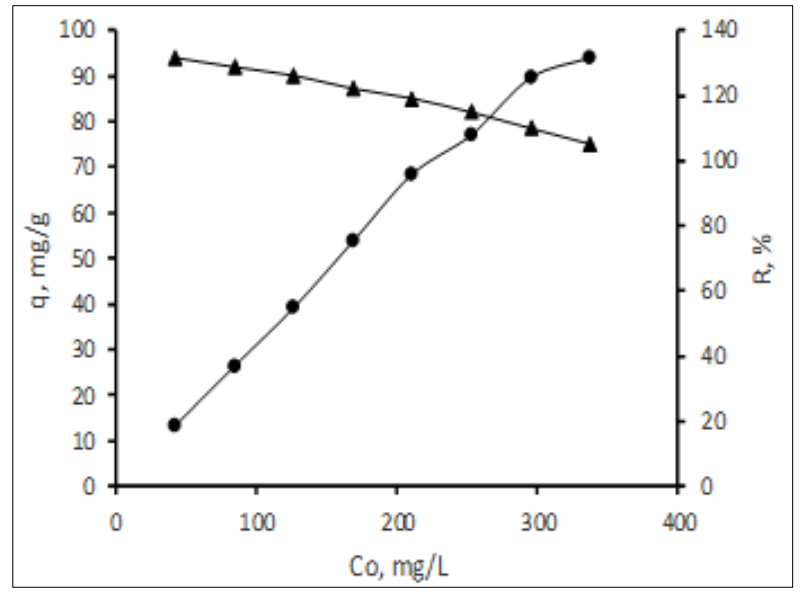

Figure 4. Influence of $\mathrm{Cu}(\mathrm{II})$ initial concentration $\left(\mathrm{C}_{0}\right)$ on the $\mathrm{Cu}$ (II) sorption in the batch sorption system $\mathrm{Cu}(\mathrm{II})$ - acrylic copolymer with amidoethylenamine groups; $(\bullet) \mathrm{q}=\mathrm{f}\left(\mathrm{C}_{0}\right) ;(\boldsymbol{\Delta}) \mathrm{R}=\mathrm{f}\left(\mathrm{C}_{0}\right) ;$ (sorbent dose $=2 \mathrm{~g} / \mathrm{L}$, time $\left.=24 \mathrm{~h}, \mathrm{t}=20^{\circ} \mathrm{C}\right)$

At the same time, due to the increasing gradient of concentration playing the leader role in the overcoming of the resistance to the mass transfer, the amount of $\mathrm{Cu}((\mathrm{II})$ retained on the acrylic copolymer with amidoethylenamine groups has increased 7.2 times for an increase of initial concentration of $\mathrm{Cu}(\mathrm{II})$ from $42.24 \mathrm{mg} / \mathrm{L}$ to $338 \mathrm{mg} / \mathrm{L}$.

\subsubsection{Influence of contact time}

The contact time effect in the acrylic sorbent with amidoethylenamine groups $-\mathrm{Cu}$ (II) batch sorption system is recorded in Figure 5. 


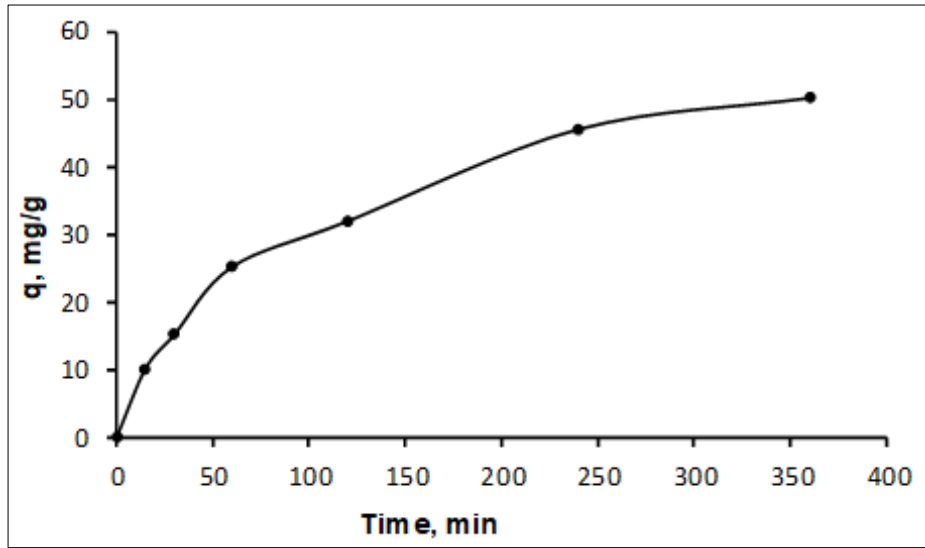

Figure 5. The effect of contact time on the $\mathrm{Cu}(\mathrm{II})$ retention by the acrylic resin functionalized with amidoethylenamine groups $\left(\mathrm{C}_{0}=126.72 \mathrm{mg} \mathrm{Cu}(\mathrm{II}) / \mathrm{L}\right.$; sorbent $\left.\operatorname{dose}=2 \mathrm{~g} / \mathrm{L}\right)$

Figure 5 points out the increasing tendency of the $\mathrm{Cu}(\mathrm{II})$ amounts sorbed on the targeted chelating polymer at the increase of contact time from 0 to $400 \mathrm{~min}$. The increase is sharp in the first range of about 100 min and slight as the $\mathrm{Cu}$ (II) sorption process tends to reach equilibrium. In good agreement with the well known great stability of the copper amine complexes, the high strength of the bond by which $\mathrm{Cu}$ (II) has been retained on the tested functionalized copolymer is indicated by the decreasing concentration of $\mathrm{Cu}(\mathrm{II})$ remaining in the solution.

\subsubsection{Equilibrium and kinetics modelling \\ Sorption isotherms}

Starting from the wide applicability and the high value of the provided informations, the $\mathrm{Cu}$ (II) sorption data have been characterized with the aid of models of Langmuir and Freundlich isotherms (Table 1)

Table 1. A brief presentation of the isotherm models used in present work for the description of the sorption equilibrium

\begin{tabular}{|c|c|}
\hline Langmuir isotherm [22] & Freundlich isotherm [23] \\
\hline $\begin{array}{l}\text { Langmuir equation } \\
q=q_{0} \frac{K_{I} \cdot C}{1+K_{I} \cdot C} \\
\text { Langmuir parameters: } \\
\text { qo is the maximum capacity of sorption, corresponding to } \\
\text { the sorbent surface and } \mathrm{K}_{\mathrm{L}} \text { is the equilibrium constant } \\
\text { (Langmuir) } \\
\text { Determination of the Langmuir constants: } \\
\text { from the intercept and slope of the corresponding linear } \\
\text { Langmuir plot, expressed by the following equation: } \\
\frac{1}{q}=\frac{1}{q_{0} \cdot K_{I} \cdot C}+\frac{1}{q_{0}} \\
\text { Assumptions: } \\
\text { - the restriction of sorption to a monolayer; } \\
\text { - the homogeneity of the sorbent surface; } \\
\text {-the existence of a limited number that are equivalent } \\
\text { from energetic and molecules accessibility point of view; } \\
\text { - the reversibility of the sorption; } \\
\text { - absence of the interactions between the retained species }\end{array}$ & $\begin{array}{l}\text { Freundlich equation } \\
\qquad \mathrm{q}=\mathrm{K}_{\mathrm{F}} \cdot \mathrm{C}^{\mathrm{lin}} \\
\frac{\text { Freundlich parameters }}{K_{F} \text { and } n \text { are related to all factors affecting the retention }} \\
\text { process: sorption capacity }\left(K_{F}\right) \text { and energy of sorption }(n) \text {, } \\
\text { respectively. } \\
\text { Determination of the Freundlich constants: } \\
\text { - from the plot of the logarithmic Freundlich equation: } \\
\lg \mathrm{q}=\lg \mathrm{K}_{F}+\frac{1}{n} \lg C \\
\text { Assumptions : } \\
\text { - the sorption occurs on heterogeneous surface of an } \\
\text { sorbent with interaction between the sorbate molecules }\end{array}$ \\
\hline
\end{tabular}


The relevant parameters for $\mathrm{Cu}(\mathrm{II})$ sorption on the acrylic copolymer functionalized with amidoethylenamine groups were calculated on the basis of the corresponding linearized Langmuir and Freundlich isotherms, given in Figure 6. The yielded values are listed in Table 2.

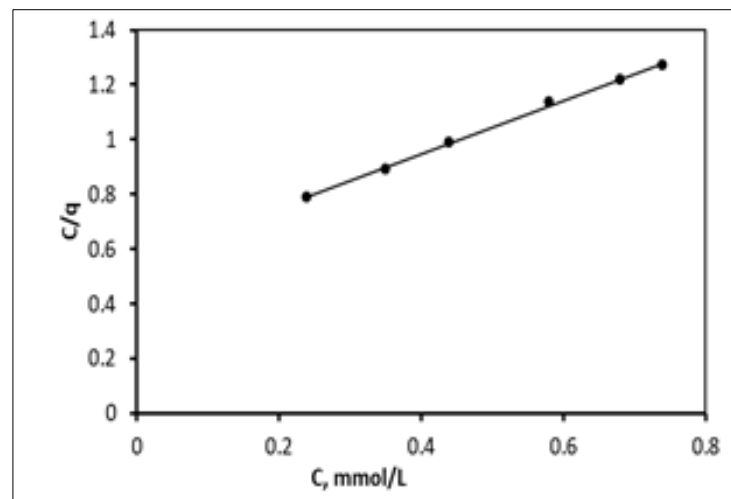

(a)

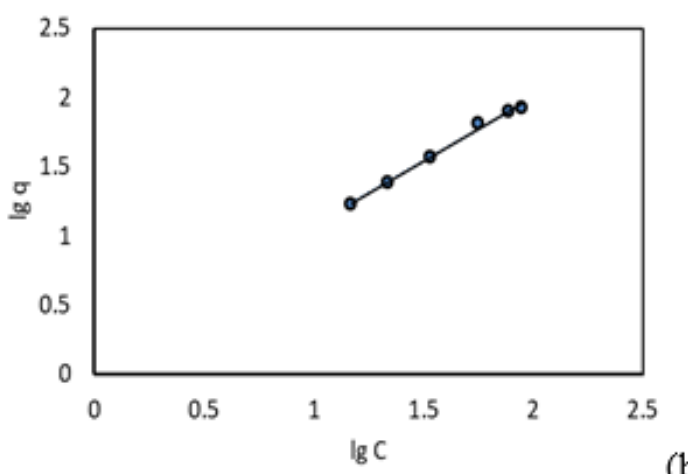

(b)

Figure 6. Linearized Langmuir (a) and Freundlich (b)isotherm plots for the sorption of $\mathrm{Cu}$ (II) on tested functionalized acrylic copolymer $\left(\right.$ dose $=2 \mathrm{~g} / \mathrm{L}$, time $\left.=24 \mathrm{~h}, \mathrm{t}=20^{\circ} \mathrm{C}\right)$

Table 2. Isotherm parameters

\begin{tabular}{|ccc|ccc|}
\hline \multicolumn{3}{|c|}{ Langmuir isotherm } & \multicolumn{3}{c|}{ Langmuir isotherm } \\
\hline $\begin{array}{c}\mathrm{K}_{\mathrm{L}} \\
\left(\mathrm{L} \cdot \mathrm{mol}^{-1}\right)\end{array}$ & $\begin{array}{c}\mathrm{q}^{-1} \\
\left(\mathrm{mg} \cdot \mathrm{g}^{-1}\right)\end{array}$ & $\mathrm{R}^{2}$ & $\mathrm{~K}_{\mathrm{F}}$ & $1 / \mathrm{n}$ & $\mathrm{R}^{2}$ \\
\hline 1751.31 & 65.21 & 0.9981 & 5.12 & 0.63 & 0.9965 \\
\hline
\end{tabular}

The high value of the KL Langmuir constant in Table 2 suggests that in the sorption process are involved strong interactions. According to Table 2, the maximum capacity of sorption, $\mathrm{q}_{0}$, has a significant value, highlighting the potential applicability of the proposed sorbent for remediation purpose. The $\mathrm{K}_{\mathrm{F}}$ parameter in Table 2 is associated with the sorption capacity as Langmuir $\mathrm{q}_{0}$. As can be seen from Table 2, the value of $1 / \mathrm{n}<1$, being consistent with the chemical nature of the sorption process. Table 2 also shows that the calculated values of the corresponding correlation coefficients of linear regression (R2) were very close. This signifies that the $\mathrm{Cu}$ (II) sorption process on the acrylic copolymer functionalized with amidoethylenamine groups may be properly depicted by both Langmuir and Freundlich isotherms. This finding suggests that the surface of the proposed sorbent is neither typically homogeneous nor typically heterogeneous and indicates the multilayer manner of the sorption process. A similar behavior has been reported in the literature for the retention of $\mathrm{Cu}$ (II) ions on a chelating sorbent prepared by bonding (2- acrylamido- 2 - methylpropanesulfonic acid) onto silica gel [24].

\section{Kinetics modelling}

Taking into account their relevance and significance, the experimental results of this study have been correlated with Lagergren (pseudo-first order) and Ho (pseudo-second order) kinetic models [25, 26]. The fundamental assumption of both models is the proportionality between the rate of sorption and the number of free sites on the surface of the sorbent in the proper power (first or second). The equations of the pseudo-first order and pseudo-second order kinetic model are as follows:

$$
\begin{array}{lc}
\text { Lagergren pseudo- first-order: } & q_{t}=q_{e}\left(1-e^{-k_{1} t}\right) \\
\text { Pseudo-second-order } & 1 / \mathrm{qt}=1 / \mathrm{h}+(1 / \mathrm{qe}) . \mathrm{t}
\end{array}
$$


where qt and qe are the amounts of $\mathrm{Cu}(\mathrm{II})$ sorbed $(\mathrm{mg} / \mathrm{g})$ at time $\mathrm{t}$ and at equilibrium, respectively, and $\mathrm{k}_{1}\left(\mathrm{~min}^{-1}\right)$ and $\mathrm{k}_{2}(\mathrm{mg} / \mathrm{g} \cdot \mathrm{min})$ are the rate constants of pseudo-first-order and pseudo-second-order sorptions, respectively, and $\mathrm{h}=\mathrm{k}_{2} \cdot \mathrm{q}(\mathrm{mg} / \mathrm{g} \cdot \mathrm{min})$ can be regarded as the initial sorption rate constant of the pseudo-second-order sorption $\left(\mathrm{g} / \mathrm{mg}^{*} \mathrm{~min}\right)$.

The corresponding kinetic parameters derived from the plots of the liniarized forms of the applied kinetic equations (Figure 7) are summarized in Table 3. Their correlation coefficients $\left(\mathrm{R}_{2}\right)$ are also recorded in Table 3.

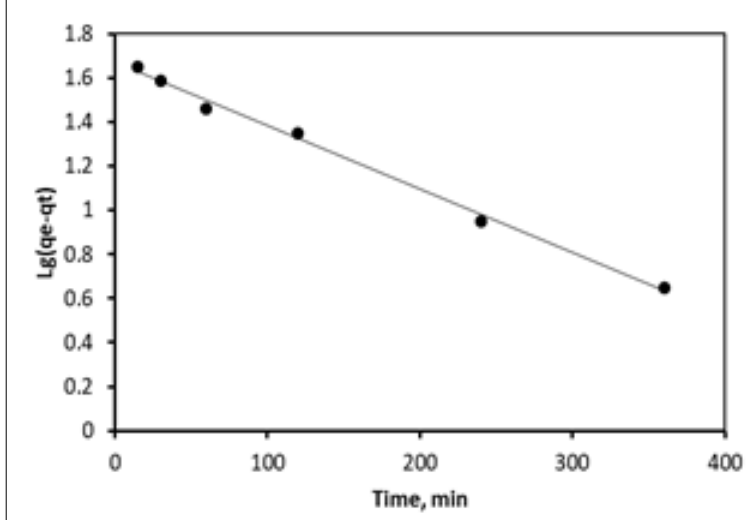

(a)

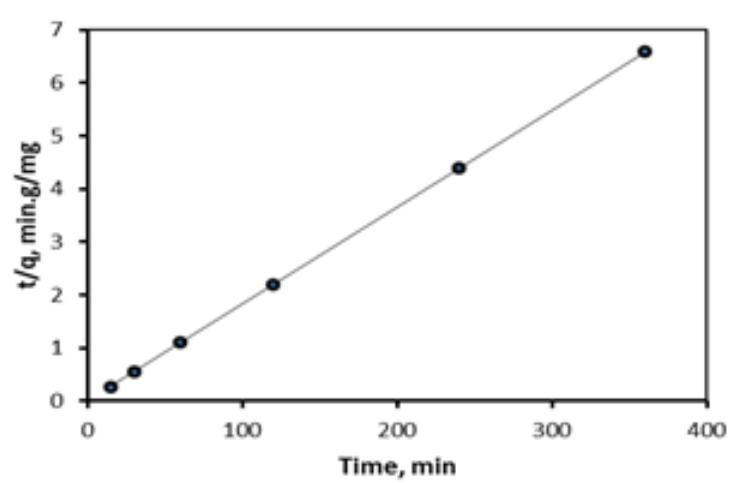

(b)

Figure 7. Liniarized plots of the pseudo- first order (a) and pseudo - second order (b) equations for the sorption of $\mathrm{Cu}(\mathrm{II})$ on the acrylic copolymer functionalized with amidoethylenamine groups

Table 3. Kinetic description of $\mathrm{Cu}(\mathrm{II})$ retention by the proposed chelating sorbent

\begin{tabular}{|c|c|l|c|c|c|c|}
\hline \multicolumn{3}{|c|}{ Pseudo- first order } & \multicolumn{4}{c|}{ Pseudo-second order } \\
\hline $\mathrm{k}_{1}, \mathrm{~min}^{-1}$ & $q_{0,} \mathrm{mg} / \mathrm{g}$ & $\mathrm{R}^{2}$ & $\begin{array}{c}\mathrm{k}_{2} \\
\mathrm{~g} / \mathrm{mg} \cdot \mathrm{min}\end{array}$ & $\begin{array}{c}\mathrm{h}, \\
\mathrm{mg} / \mathrm{g} \cdot \mathrm{min}\end{array}$ & $\begin{array}{c}\mathrm{q}_{0,} \\
\mathrm{mg} / \mathrm{g}\end{array}$ & $\mathrm{R}^{2}$ \\
\hline $6.67 \times 10^{-3}$ & 46.93 & 0.9852 & $2.76 \times 10^{-3}$ & 0.8256 & 54.64 & 0.9999 \\
\hline
\end{tabular}

In accordance with Table 3, the value of $\mathrm{R}_{2}$ for the pseudo - second order kinetic model is higher than that of the pseudo - first order model. This finding lead to the following conclusions: (i) the process of $\mathrm{Cu}$ (II) retention on the acrylic copolymer with amidoethylenamine groups follows best a pseudosecond order kinetics; (ii)the dominant mechanism may be the chemisorption. Other chelating sorbents for $\mathrm{Cu}$ (II) retention had a similar behaviour [20,27].

\subsection{Fixed bed column studies}

The informations provided by the batch studies can not be extrapolated to the design of columns operating on industrial scale. The scarcity of dynamic studies reported in literature on the one hand, and the importance of these studies on the other hand highlight the stringent need for works on the behavior of the fixed bed column sorption. The dynamic studies gravitate around the breakthrough curve (the evolution of the solution concentration as a function of time or volume of the processed solution), which is the most important parameter to be determined.

In this context, the description of the performances of the $\mathrm{Cu}(\mathrm{II})$ - acrylic copolymer functionalized with amidoethylenamine groups fixed bed column sorption system has been performed by processing and modelling of the experimental breakthrough data. 


\subsubsection{Breakthrough curves}

The breakthrough curves for the dynamic sorption of $\mathrm{Cu}(\mathrm{II})$ ions from aqueous solutions on the acrylic copolymer functionalized with amidoethylenamine groups are presented in Figure 8 as the relation between normalized concentration( $\mathrm{C}_{t}-$ effluent $\mathrm{Cu}$ (II) concentration)/ $\mathrm{C}_{0}$ - influent $\mathrm{Cu}$ (II) concentration). According to Figure 8, the resulting curves are characterized by a "S" shape, that is strongly dependent on the influent concentration of $\mathrm{Cu}(\mathrm{II})$.

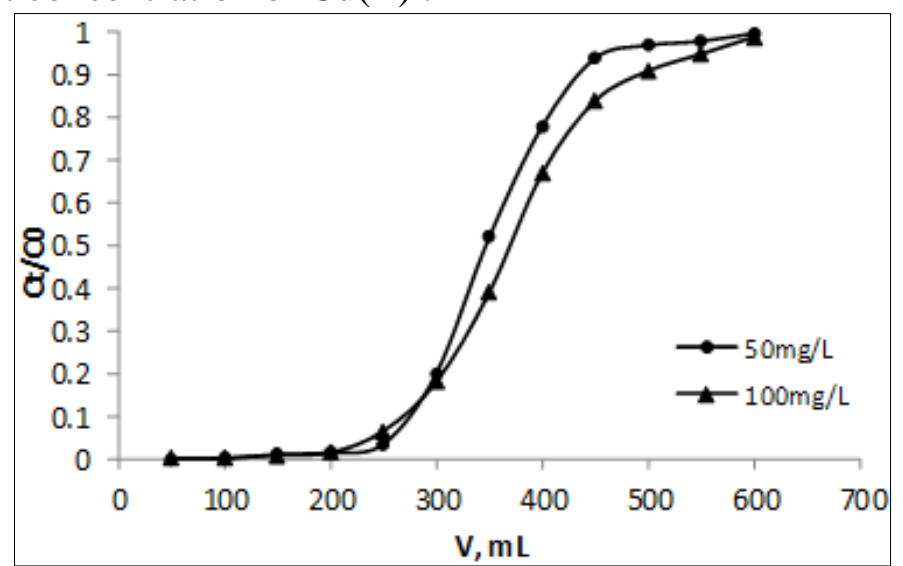

Figure 8. Breakthrough curves of the sorption of $\mathrm{Cu}$ (II)

on tested acrylic copolymer at varied concentrations

of influent $(\cdot 50 \mathrm{mg} / \mathrm{L} ; \boldsymbol{\Delta}-100 \mathrm{mg} / \mathrm{L})$

The two significant points of the experimental breakthrough curves are usually analyzed on the basis of the following parameters [28]:

-the breakthrough time $\left(\mathrm{t}_{\mathrm{b}}, \mathrm{min}\right)$ that represents the time required to reach the breakthrough point (the point in which $\mathrm{Cu}$ (II) reaches the column end and leaves with the effluent of column),considered on the basis of the effluent discharge limit for $\mathrm{Cu}(\mathrm{II})$;

- the saturation time $\left(\mathrm{t}_{\mathrm{sat}}, \mathrm{min}\right)$ that is defined as time required to the saturation point reaching, meaning the time to which the effluent concentration remains close to influent concentration.

On the basis of breakthrough time $\left(\mathrm{t}_{\mathrm{b}}\right)$ and saturation time $\left(\mathrm{t}_{\mathrm{s}}\right)$, the active surface of the sorbent bed in which the sorption process take place, namely, the mass transfer zone (MTZ, cm) has been computed by means of the following equation:

$$
\mathrm{MTZ}=\mathrm{H}\left(1-\frac{t_{b}}{t_{\text {sat }}}\right)
$$

where $\mathrm{H}$ is length of the sorbent bed $(\mathrm{cm})$.

The obtained values for the breakthrough parameters are listed in Table 4. It is possible to observe from Table 4 that the $\mathrm{Cu}$ (II)sorption at breakthrough and saturation has been faster at high influent concentration, which yields a more powerful driving force. The decreased values of MTZ pointed out a lower capability of $\mathrm{Cu}(\mathrm{II})$ treatment at increased concentrations. In addition, an increase in the concentration of influent is correlated with a higher amount of copper ions for the same amount of acrylic copolymer, resulting in a lower volume of solution before the sorbent becomes saturated [29].

Table 4. Experimental parameters of the breakthrough curves for fixed bed column sorption of $\mathrm{Cu}(\mathrm{II})$ on the tested sorbent

\begin{tabular}{|c|c|c|c|c|c|}
\hline $\begin{array}{c}\text { Influent } \\
\text { concentration } \\
C_{0}(\mathrm{mg} / \mathrm{L})\end{array}$ & $\begin{array}{c}t_{\mathrm{b}}(\mathrm{min}) \\
\left(C_{0} / C_{0}\right. \\
=0.1)\end{array}$ & $V_{\mathrm{b}}(\mathrm{mL})$ & $\begin{array}{c}t_{\mathrm{s}}(\mathrm{min})\left(C_{1} / C_{0}\right. \\
=0.9)\end{array}$ & $V_{\mathrm{s}}(\mathrm{mL})$ & $\begin{array}{c}\mathrm{MTZ} \\
(\mathrm{cm})\end{array}$ \\
\hline 50 & 106 & 243.9 & 194 & 485 & 3.17 \\
\hline 100 & 96.2 & 215 & 165 & 454.5 & 2.83 \\
\hline
\end{tabular}

where $C_{t}$ and $C_{0}$ are the effluent and influent metal concentration $(\mathrm{mg} / \mathrm{L}$. 


\subsubsection{Modelling of fixed bed column}

The experimental breakthrough data have been verified by both Thomas and Yoon-Nelson models.

The most commonly used model in the dynamic studies is the Thomas model which assumes that the rate driving force obeys second-order reversible reaction kinetics [30]. The linearized form of Thomas equation is [31]:

$$
\ln \left(\frac{\mathrm{C}_{0}}{\mathrm{C}_{\mathrm{t}}}-1\right)=\frac{\mathrm{K}_{\mathrm{T}} \cdot \mathrm{q}_{\mathrm{O}(\mathrm{T})} \cdot \mathrm{m}}{\mathrm{F}}-\frac{\mathrm{K}_{\mathrm{T}} \cdot \mathrm{C}_{0}}{\mathrm{~F}} \cdot \mathrm{V}
$$

where $\mathrm{C}_{0}$ is the initial metal ion concentration $(\mathrm{mg} / \mathrm{L}) ; \mathrm{Ct}$ is the equilibrium concentration $(\mathrm{mg} / \mathrm{L})$ at time $\mathrm{t}$ (min); $\mathrm{kT}$ is the Thomas constant $(\mathrm{L} / \mathrm{min} \cdot \mathrm{mg}) ; \mathrm{F}$ is the volumetric flow rate $(\mathrm{L} / \mathrm{min}) ; \mathrm{qo}(\mathrm{T})$ is the maximum column capacity ( $\mathrm{mg} / \mathrm{g})$, determined by the Thomas model; $\mathrm{m}$ is mass of sorbent $(\mathrm{g}) ; \mathrm{V}$ is the volume $(\mathrm{L})$.

The main assumption of the Yoon - Nelson model is that the probability of the decrease of the sorption rate for each sorbate molecule is proportional to the sorbate breakthrough probability on the sorbent [32]. TheYoon-Nelson model is based on an equation having the following linearized form [33]:

$$
\ln \left(\frac{\mathrm{C}_{\mathrm{t}}}{\mathrm{C}_{0}-\mathrm{C}_{\mathrm{t}}}\right)=\mathrm{k}_{\mathrm{YN}} \cdot \mathrm{t}-\tau \cdot \mathrm{k}_{\mathrm{YN}}
$$

where $\mathrm{C}_{0}$ is the initial metal ion concentration $(\mathrm{mg} / \mathrm{L}) ; \mathrm{C}_{\mathrm{t}}$ is the equilibrium concentration $(\mathrm{mg} / \mathrm{L})$ at time $\mathrm{t}(\mathrm{min}) ; \mathrm{kYN}$ is Yoon-Nelson rate constant (min-1); $\tau$ is time required for $50 \%$ sorbate breakthrough; $\mathrm{t}$ is sampling time ( $\mathrm{min})$

According to the Yoon-Nelson model, the amount of metal ion sorbed in a fixed bed is half of the total metal ion entering the adsorption bed within $2 \tau$ period [34]. In this context, for a given bed, the column sorption capacity in the Yoon-Nelson model, $\mathrm{q}_{0}(\mathrm{YN})$ can be computed with the following equation:

$$
\mathrm{q}_{0 \mathrm{Y}_{\mathrm{n}}}=\frac{\mathrm{q}_{(\text {totat })}}{\mathrm{m}}=\frac{\frac{1}{2} \mathrm{C}_{0}[(\mathrm{r} / 1000) \times 2 \tau]}{\mathrm{m}}=\frac{\mathrm{C}_{0} \cdot \mathrm{r} \cdot \tau}{1000 \cdot \mathrm{m}}
$$

where $\mathrm{C}_{0}$ is the initial concentration $(\mathrm{mg} / \mathrm{L}) ; \mathrm{r}$ is flow rate $(\mathrm{mL} / \mathrm{min}) ; \mathrm{m}$ is weight of sorbent $(\mathrm{g})$ and $\tau$ is time required for $50 \%$ sorbate breakthrough.

The fixed bed sorption of $\mathrm{Cu}$ (II) on the acrylic copolymer functionalized with amidoeth-ylenamine groups is described in Table 5 by means of Thomas and Yoon - Nelson model parameters, derived from the slope and the intercept of the corresponding liniar equations plots (Figure 9)

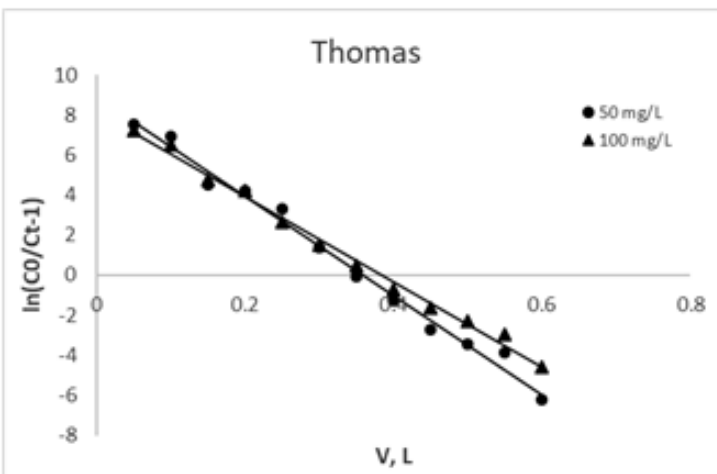

(a)

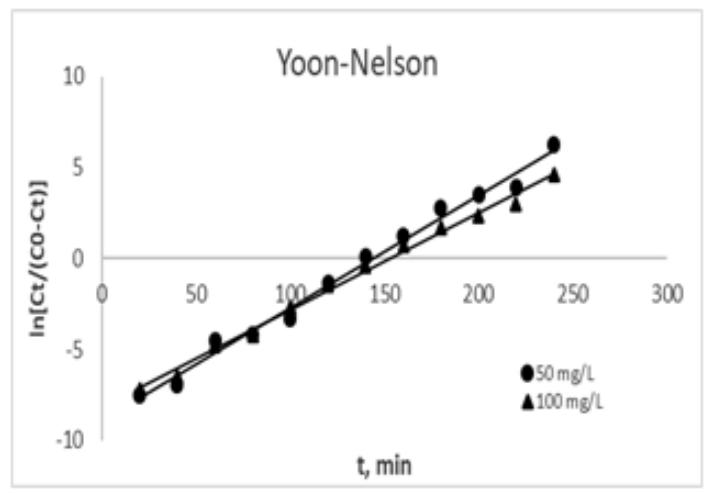

(b)

Figure 9. Linear Thomas(a) and Yoon-Nelson(b) plots for column sorption of $\mathrm{Cu}(\mathrm{III})$ on the tested chelating polymer at 2 initial concentrations 
Conforming to Table 5, the obtained values of the linear regression coefficients $\left(\mathrm{R}_{2}\right)$ for the Thomas plots are higher than those for the Yoon - Nelson plots. This means that the fixed bed column sorption of $\mathrm{Cu}$ (II) on the proposed functionalized copolymer is best described by the Thomas model, based on the Langmuir sorption/ desorption model and a second - order reversible reaction kinetics.

Table 5. Thomas and Yoon - Nelson model parameters

\begin{tabular}{|c|c|c|c|c|c|c|c|}
\hline \multirow{2}{*}{$\begin{array}{c}\mathrm{C}_{0,} \\
(\mathrm{mg} / \mathrm{L})\end{array}$} & \multicolumn{3}{|c|}{ Thomas model } & \multicolumn{4}{|c|}{ Yoon-Nelson model } \\
\hline & $\begin{array}{c}\mathrm{K}_{\mathrm{T}} \\
\text { (L/min-mg) }\end{array}$ & $\begin{array}{c}\mathrm{q} 0(\mathrm{~T}), \\
(\mathrm{mg} / \mathrm{g})\end{array}$ & $\mathrm{R}^{2}$ & $\begin{array}{c}\mathrm{kyn}, \\
(\mathrm{mg} / \mathrm{g})\end{array}$ & $\tau,(\min )$ & $\begin{array}{l}\mathrm{q} 0(\mathrm{mN}), \\
(\mathrm{mg} / \mathrm{g})\end{array}$ & $\mathrm{R}^{2}$ \\
\hline 50.00 & $1.23 \cdot 10^{-3}$ & 11.40 & 0.993 & 0.053 & 154.42 & 13.24 & 0.939 \\
\hline 100.00 & $5.33 \cdot 10^{-4}$ & 24.84 & 0.989 & 0.062 & 143 & 30.28 & 0.973 \\
\hline
\end{tabular}

where: $\mathrm{k}_{\mathrm{T}}$ is Thomas rate constant and requiq $q_{0(\mathrm{~T})}$ is Thomas maxium sorption capacity
kYN is Yoon-Nelson rate constant; $\tau$ is the time for $50 \%$ breakthrough and $\mathrm{q}_{0}(\mathrm{YN})$ is Yoon-Nelson column sorption capacity

\subsection{Evaluation of the proposed chelating sorbent}

Figure 10 records the Langmuir and Thomas maximum capacity of $\mathrm{Cu}$ (II) sorption for the tested acrylic copolymer functionalized with amidoethyleneamine groups and other chelating sorbents. Although the sorption capacity is strongly dependent on the nature of the sorbent, Figure 10 clearly shows thar the proposed functionalized copolymer is very compatible with other sorptive materials. The chelating copolymer under study is eligible as a performance sorbent for $\mathrm{Cu}$ (II) removal- recovery from aquatic environments.

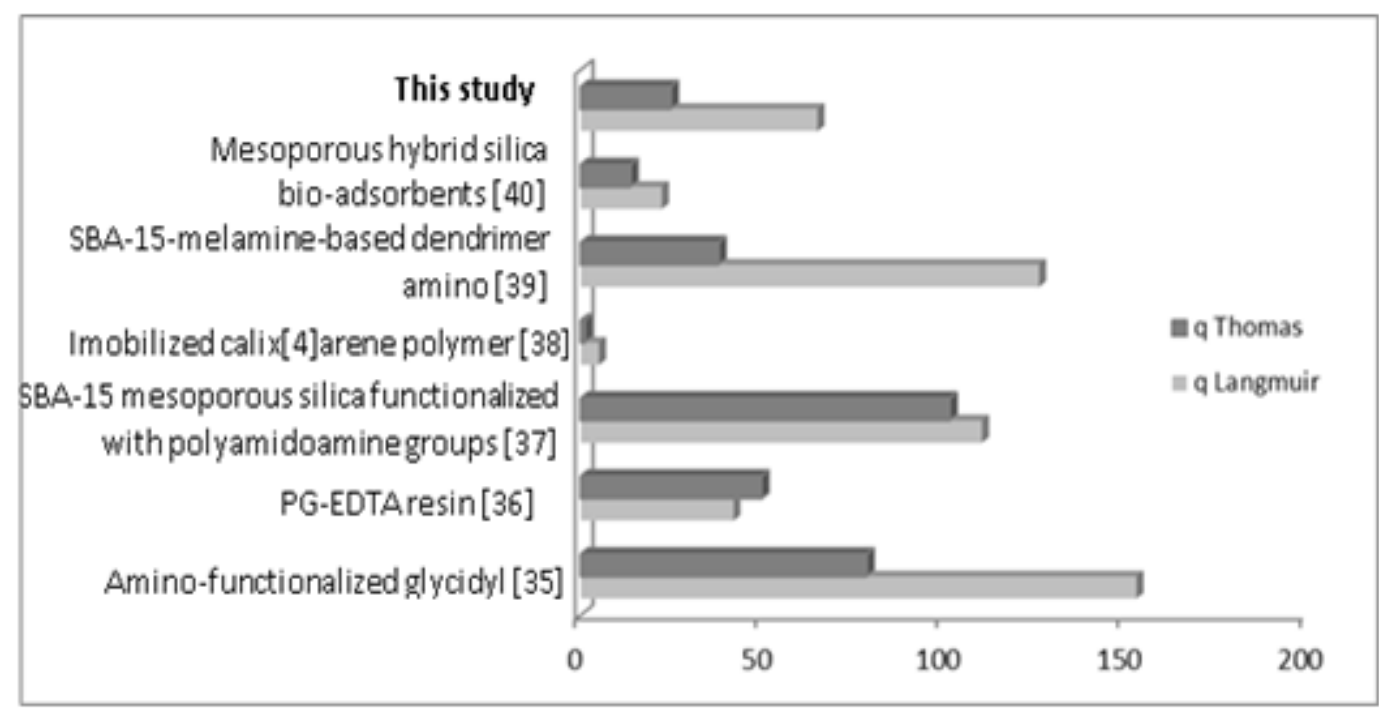

Figure 10. Comparison of the proposed acrylic copolymer functionalized with amidoethyleneamine groups with other reported chelating sorbents for $\mathrm{Cu}$ (II) removal

\subsection{Practical applicability}

\subsubsection{Reusability studies}

In order to check the reusability of the tested chelating acrylic copolymer, the $\mathrm{Cu}$ (II) desorption and the recycling of the sorbent have been studied in batch conditions (Figure 10). According to the literature findings, the desorbing agent, which the best fulfill the economic and ecological requirements is $\mathrm{HCl}$ [40]. Because of this, copper was desorbed from the metal loaded acrylic copolymer functionalized with amidoethyleneamine groups by using $0.1 \mathrm{M} \mathrm{HCl}$. As can be seen from Figure 11, successive sorp-tion- 
desorption cycles have demonstrated the possibility of chelating polymer regeneration and its reuse at least 6 times with a copper recovery efficiency of over $90 \%$.

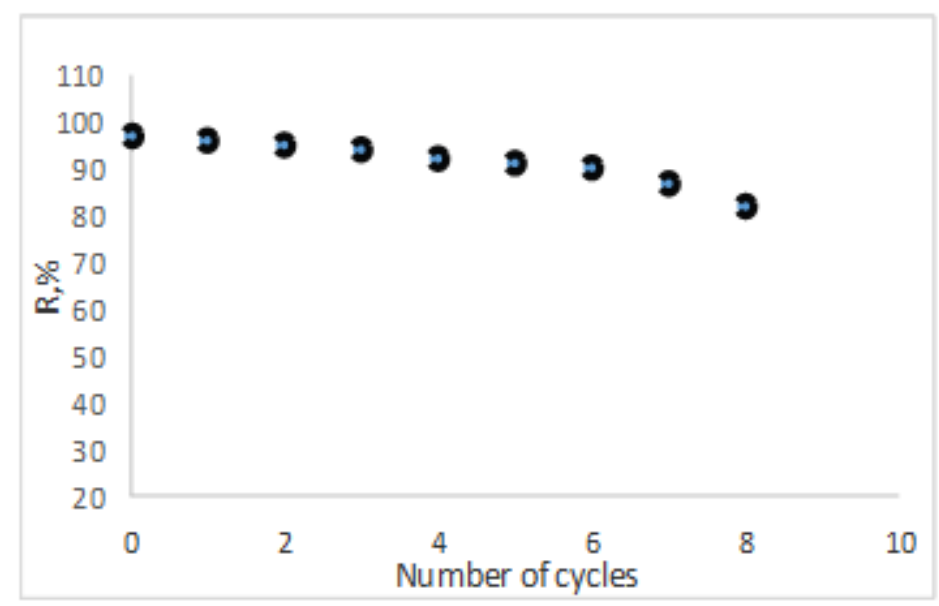

Figure 11. Repeated use studies

\subsubsection{Treatment of sample of real wastewater}

In order to evaluate the efficiency of the acrylic copolymer functionalized with amidoethyleneamine groups in the treatment of real wastewaters, the removal of $\mathrm{Cu}$ (II) from a wastewater sample originating from a municipal deposit of wastes collecting has been investigated in fixed bed column conditions (Table 6). The results in Table 6 distinctly shows that the proposed chelating copolymer use results in a significant improvement of the tested wastewater quality, with a special mention on the retention of the $\mathrm{Cu}(\mathrm{II})$ entire amount

Table 6. Quality of the tested wastewater before and after treatment with the chelating copolymer under study

\begin{tabular}{|l|c|c|}
\hline Wastewater parameters & Before treatment & After treatment \\
\hline $\mathrm{pH}$ & 4.01 & 6.87 \\
\hline Turbidity (NTU) & 0.85 & 0.05 \\
\hline Total hardness $\left({ }^{\circ} \mathrm{G}\right)$ & 25 & 3.15 \\
\hline Chloride $(\mathrm{mg} / \mathrm{L})$ & 82 & 25 \\
\hline $\mathrm{CCOCr}\left(\mathrm{mgO}_{2} / \mathrm{L}\right)$ & 95 & $<30$ \\
\hline $\mathrm{Cu}(\mathrm{II})(\mathrm{mg} / \mathrm{L})$ & 10 & 0.00 \\
\hline $\mathrm{Mn}$ (II) $(\mathrm{mg} / \mathrm{L})$ & 2.75 & 0.02 \\
\hline $\mathrm{Zn}$ (II) $((\mathrm{mg} / \mathrm{L})$ & 1.25 & 0.01 \\
\hline
\end{tabular}

According to Figure 11 and Table 6, the acrylic copolymer functionalized with amidoethyleneamine groups can be cyclic used, with benefits of ecological (removal of $\mathrm{Cu}$ (II) form wastewaters) and economical $(\mathrm{Cu}(\mathrm{II})$ recovery in concentrated metal solutions) relevance (Figure 12).

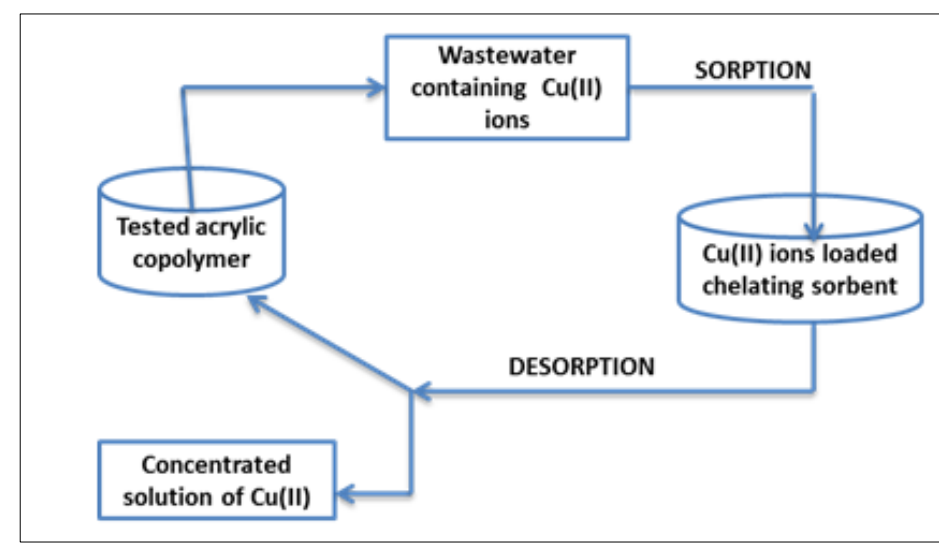

Mater. Plast., 57 (4), 2020, 258-274
Figure 12. Schematic representation of the potential cyclic use of the tested sorbent 


\section{Conclusions}

The results of this work give the evidence of the possible benefits of using an acrylic copolymer functionalized with amidoethyleneamine groups for the $\mathrm{Cu}$ (II) removal-recovery-recycling. The initial $p \mathrm{H}$ of the solution, initial metal ion concentration and contact time have marked effect on the $\mathrm{Cu}$ (II) batch sorption process. The equilibrium data fit well with both Langmuir and Freundlich isotherms. The process of $\mathrm{Cu}$ (II) retention on the acrylic copolymer with amidoethylenamine groups follows best a pseudo- second order kinetics. The Thomas model is the optimal solution for the description of the proposed chelating copolymer fixed bed column. Successive sorption-desorption cycles in batch conditions have demonstrated the possibility of chelating polymer regeneration and its reuse at least 6 times. Dynamic studies with real wastewater showed an efficiency of $\mathrm{Cu}(\mathrm{II})$ removal of $100 \%$ for and a promising amelioration of the quality of wastewater .

\section{Reference}

1. STERN,B.R., SOLIZ,M., KREWSKI, D., AGGETT, P., AW, T.C., BAKER, S., CRUMP, K., BOURSON,M., HABER, L., HERTZBERG,R., KEEN, C.,MEEK, B., RUDENKO,L., SCHOENY, R., SLOB, W., STARR, T, Copper and human health: biochemistry, genetics and strategies for modelling dose-response methodology relationships, J. Toxicol. Environ. Health B Crit. Rev., 10(3), 2007, 157222.

2.CHEN, H., DAI, G., ZHAO, J., ZHONG, A., WU, J., YAN, H., Removal of copper(II) ions by a biosorbent- Cinnamomum camphora leaves powder, J. Hazard. Mater., 177(1-3), 2010, 228 - 236.

3.BILAL, M., ALI SHAH, J., ASHGFAQ, T., GARDAZI, S.M.H., TAHIR, A.A., HAROON, H., MAHMOOD, Q., Waste biomass adsorbents for copper removal from industrial wastewater-A review, J. Hazard. Mater., 263(2), 2013, 322- 333.

4.AL-SAYDEH, S.A., NAAS, M.H., ZAIDI, S.J., Copper removal from industrial wastewater: a comprehensive review, J. Ind. Eng. Chem., 56, 2017, 35 - 44.

5. BHATNAGAR, A., VILAR, V.P.J., BOTELHO, C.M.S., BOAVENTURA, R.A., A review of the use of red mud as adsorbent for the removal of toxic pollutants from water and wastewater, Environ.Technol., 32(3-4), 2010, 231-249.

6.CAROLIN, F.C., SENTHIL KUMAR, P., SARAVANAN, A., JANET JOSHIBA, G., NAUSHAD, MU., Efficient techniques for the removal of toxic heavy metals from aquatic environment: a review, J. Env. Chem. Eng.,5(3),2107,2782 - 2799.

7. PAN, B. PAN, B., ZHANG, W., LV, L., ZHANG Q, ZHENG, S., Development of polymeric and polymer based hybrid adsorbents for pollutant removal, Chem. Eng. J.,151(1-3),2009,19- 29.

8. ZHANG, YU., CHEN, Y., WANG, C., WEI, Y., Immobilization of 5-aminopyridine-2-tetrazole on cross-linked polystyrene for the preparation of a new adsorbent to remove heavy metal ions from aqueous solution, J. Hazard. Mater., 276, 2014, 129- 137.

9. KALAIVANI, S. S., VIDHYADEVI, T., MURUGESAN, T.V.A., TIRUVENGADAVARI, K.V.T., ANURACHA, D., RAVIKUMAR, L., SIVANESAN, L., The use of new modified poly(acrylamide) chelating resin with pendent benzothiazole groups containing donor atoms in the removal of heavy metal ions from aqueous solutions, Water Resour. Ind., 5, 2014, 21 -35.

10. CEGLOWSKI, M., SCHROEDER, G., Removal of heavy metal ions with the use of chelating polymers obtained by grafting pyridine-pyrazole ligands onto polymethylhydrosiloxane, Chem. Eng. J., 259, 2015, 885-893.

11. CEGLOWSKI, M., SCHROEDER, G., Preparation of porous resin with Schiff base chelating groups for removal of heavy metal ions from aqueous solutions, Chem. Eng. J., 263, 2015, $402-411$.

12. AN, F.-Q., WU, R.-Y., LI, M., HU, T.-P., GAO, J.-F., YUAN, Z.G., Adsorption of heavy metal ions by iminodiacetic acid functionalized D301 resin: Kinetics, isotherms and thermodynamics, React. Funct. Polym., 118, 2017, 42-50. 
13. JIWEI, M.S., CHAOZHAN, W., YINMAO, W., Preparation of dual-function chelating resin with high capacity and adjustable adsorption selectivity to variety of heavy metal ions, J. Taiwan Inst. Chem. Eng., 91, 2018, $532-538$.

14. NEAGU, V., PĂDURARU, C., BUNIA, I., TOFAN, L., Platinum(IV) recovery from chloride solution by functionalized acrylic copolymers, J. Environ. Manage., 91(1), 2009, 270 - 276.

15.NEAGU, V., BUNIA, I., Synthesis and morphological characterization of ethylacrylate: acrylonitrile:divinylbenzene copolymers. Rev. Roum Chim., 54(11), 2009, 1041 - 1049.

16. ZHANG, X., HUANG, Q., LIU, M., TIAN, J., ZENG, G., LI, Z., WANG, K., ZHANG, Q., WAN, Q., DENG,F., WEI, Y., Preparation of amine functionalized carbon nanotubes via a bio-inspired strategy and their application in Cu2+ removal, Appl. Surf. Sci., 343, 2015, 19-27.

17. FAN, C., LI, K., LI, J., YING, D., WANG, Y., JIA, J., Comparative and competitive adsorption of $\mathrm{Pb}$ (II) and $\mathrm{Cu}(\mathrm{II})$ using tetraethylenepentamine modified chitosan/ $\mathrm{CoFe}_{2} \mathrm{O}_{4}$ particles, J. Hazard. Mater., 326, 2017, 211-220.

18. EDEBALI, S., PEHLIVAN, E., Evaluation of chelate and cation exchange resins to remove copper ions, Powder Technol., 301, 2016, 520-525.

19. ADDALA, A., BELATTAR, N., Adsorption of $\mathrm{Cu}$ and $\mathrm{Pb}$ metal ions onto chelating resin and their application in removal of lead from battery factory wastewaters, Indian J. Chem. Technol., 24(6), 2017, 601-607.

20. WANG, G., ZHANG, S., YAO, P., CHEN, Y., XU, X., LI, T., GONG, G. Removal of Pb(II) from aqueous solutions by Phytolacca americana L biomass as low cost biosorbent, Arab.J.Chem., 11(1), 2018, $99-110$.

21.DRAGAN, E.S., DINU, M.V., LISA, G., TROCHIMCZUK, A., Study of metal complexes of chelating resins bearing iminodiacetate groups, Eur. Polym. J., 45(7), 2009,2119-2130

22. LANGMUIR, I., The constitution and fundamental properties of solids and liquids, J. Am.Chem. Soc., 38(11), 1916, 2221- 2295.

23. FREUNDLICH, H.M., Uber die adsorption in lusungen, Z. Phys. Chem., 57, 1906, 385-490.

24.WANG, H., KANG, J., LIU, H., QU, J., Preparation of organically functionalized silica gel as adsorbent for copper ion adsorption, J. Environ. Sci.,21(11), 2009, 1473 - 1479.

25. LAGERGREN, S., About the theory of so-called adsorption of solid substance, Handlinger, 24, 1898, 1-39.

26. HO, Y.S., MCKAY, G., Pseudo-second order for the sorption process, Biochemistry, 34(5), 1999, 451-465.

27. HAO, Y.M., MAN, C., HU, Z.B., Effective removal of Cu (II) ions from aqueous solution by aminofunctionalized magnetic nanoparticles, J. Hazard. Mater., 184(1-3), 2010, 392 -399.

28.SHALIBAZI, A., YOUNESI, H., BADIEI, A., Functionalized SBA-15 mesoporous silica by melamine-based dendrimer amines for adsorptive characteristics of $\mathrm{Pb}(\mathrm{II}), \mathrm{Cu}$ (II) and $\mathrm{Cd}(\mathrm{II})$ heavy metal ions in batch and fixed bed column, Chem. Eng. J., 168(2), 2011, $505-518$.

29. TSAI, W.-C., DE LUNA, M.D., BERNILLO - ARRIESGADO, H.L., FUTALAN, C., COLADES, J., WAN, M.-V., Competitive adsorption of $\mathrm{Pb}(\mathrm{II}), \mathrm{Cu}(\mathrm{II})$ and $\mathrm{Ni}$ (II) from aqueous solution using chitosan-coated bentonite, Int. J. Polym. Sci., 2016, Article ID 1608939, 2016, 11 pages

30. THOMAS, H.G., Chromatography: a problem in kinetics, Ann. N.Y. Acad. Sci., 49, 1948,161 -182 31. AL-GHOUTI, M.A., KHRAISHEH, M.A.M., AHMAD, M., ALLEN, S.J., Microcolumn studies on the dye adsorption onto manganese oxides modified diatomite, J. Hazard. Mater., 146(1-2), 2007, 316327.

32.YOON, Y.H., NELSON, J.H., Application of gas adsorption kinetics-II. A theoretical model for respirator cartridge service life and its practical applications, Am. Ind. Hyg. Assoc. J., 45(8), 1984, 509511.

33. SIVAKUMAR, P., PALAMISAMY, P.N., Packed bed column studies for the removal of Acid blue 92 and Basic red 29 using non-conventional sorbent, Indian J. Chem. Technol., 16(4), 2009,301- 307 
34. GUPTA, V.K., SRIVASTAVA, S.K., TYAGI, R., Design parameters for the treatment of phenolic wastes by carbon columns (obtained from fertilizer waste material), Water Res., 34(5), 2000, 1543 1550 .

35.NASTASOVIĆ AB, JAKOVLJEVIC D, SANDIĆ Z, DORDEVIC DS, SURUČIĆ LM, KLJAJEVIĆ S, MARKOVIĆ JP, ONJIA A., Amino-functionalized glycidyl methacrylate based macroporous copolymers as metal ion sorbents, Nova Science Publishers, 2007, 79-112.

36. WANG, L., YANG, L., LI, Y., ZHANG, Y., MA, X., YE, Z., Study on adsorption mechanism of $\mathrm{Pb}$ (II) and $\mathrm{Cu}$ (II) in aqueous solution using PS-EDTA resin, Chem. Eng. J., 163(3), 2010, 364-372.

37. SHAHBAZI, A., YOUNESI, H., BADIEI, A., Batch and fixed-bed column adsorption of Cu(II), $\mathrm{Pb}$ (II) and $\mathrm{Cd}(\mathrm{II})$ from aqueous solution onto functionalised SBA-15 mesoporous silica, Can. J. Chem. Eng., 91(4), 2013, 739-750.

38. TABAKCI, M., YILMAZ, M., Sorption characteristics of $\mathrm{Cu}(\mathrm{II})$ onto immobilized calix[4] arene polymer in aqueous solutions: batch and dynamic studies, J. Hazard. Mater.,151(2-3), 2007, 331 - 338. 39.MURESEANU, M., CIOATERA, N., TRANDAFIR, I., GEORGESCU, I., FAJULA, F., GALARNEAU, A., Selective $\mathrm{Cu}^{2+}$ adsorption and recovery from contaminated water using mesoporous hybrid silica bio-adsorbents, Micropor. Mesopor. Mat., 146(1-3), 2011, 141-150.

40. CHATERJEE, A., ABRAHAM, J., Desorption of heavy metals from metal loaded sorbent and ewastes, Biotechnol. Lett., 41, 2019, 319 -333. 